Supplementary Information for:

\title{
Development of high-throughput methods for sodium-ion battery cathodes
}

Tham Adhikari, Alex Hebert, Michel Adamič, Jacqueline Yao, Karlie Potts, and Eric

$$
\text { McCalla* }
$$

Department of Chemistry, McGill University, Montreal, H3A 0B8, Canada

* Corresponding author: eric.mccalla@mcgill.ca

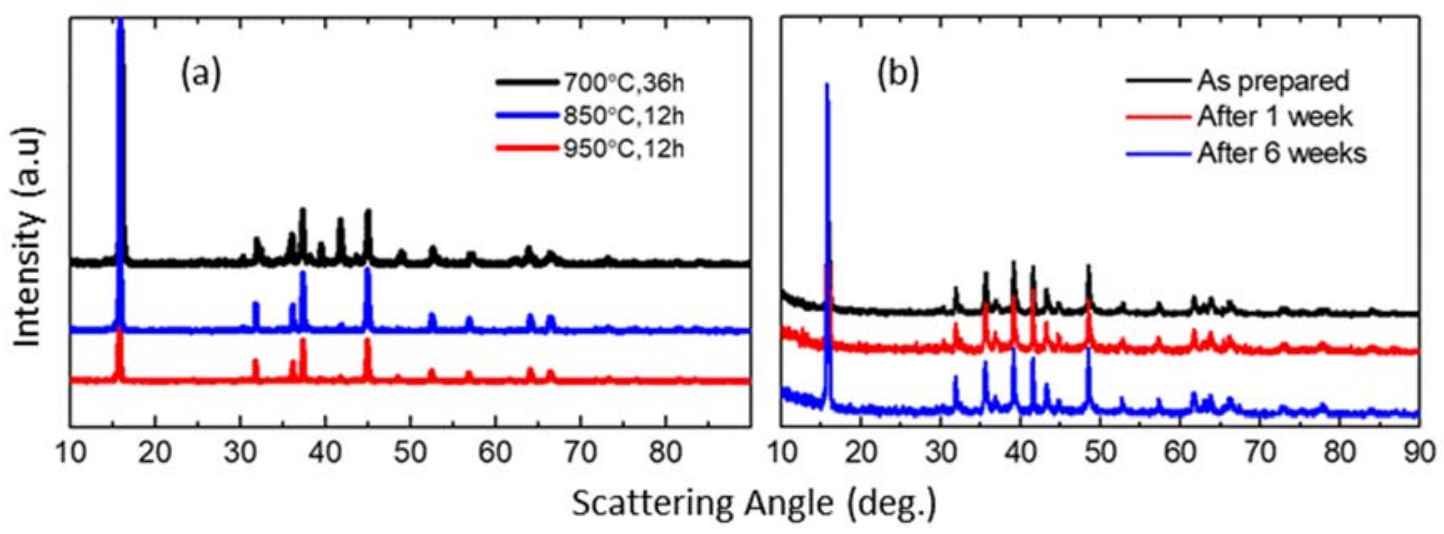

Figure S1. X-ray powder diffraction patterns of $\mathrm{O} 3-\mathrm{NaFe}_{0.5} \mathrm{Mn}_{0.5} \mathrm{O}_{2}$ : (a) sol gel method, (b) coprecipitation method, left in air for various amounts of time to test stability in air. We have found no changes in these materials with time in air up to 6 weeks. 


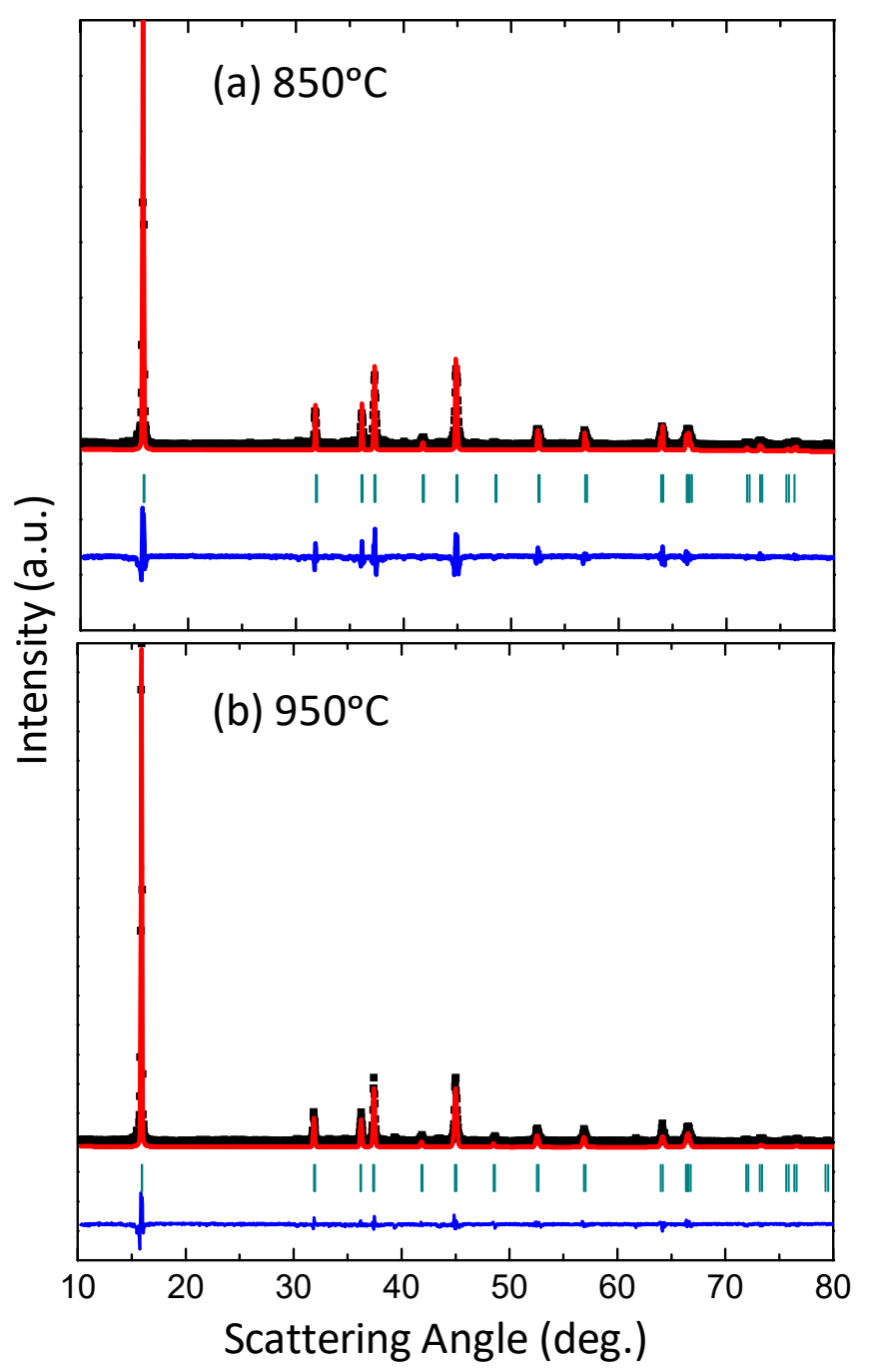

Figure S2. Observed (black) and calculated (red) XRD profiles for $\mathrm{O} 3-\mathrm{NaFe} 0.5 \mathrm{Mn} 0.5 \mathrm{O}_{2}$ obtained from the sol-gel combinatorial method, heated for $12 \mathrm{~h}$ at $850^{\circ} \mathrm{C}(\mathrm{a})$, and $950^{\circ} \mathrm{C}(\mathrm{b})$. The blue line represents the difference between the data and the fit. 


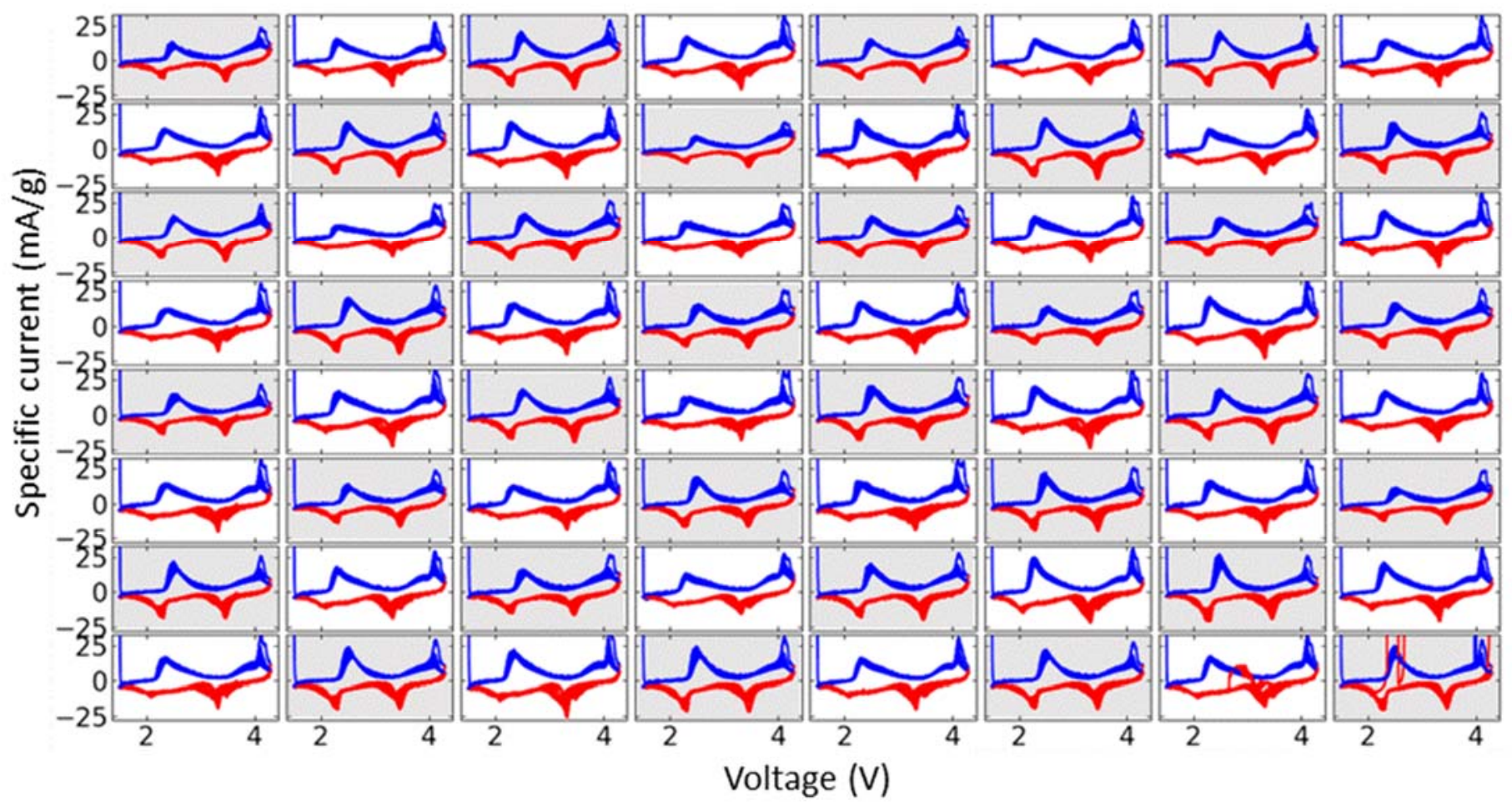

Figure S3: Cyclic voltammograms obtained for $32 \mathrm{P} 2-\mathrm{Na} 0.66 \mathrm{Fe} 0.5 \mathrm{Mn} 0.5 \mathrm{O} 2$ combinatorial samples shown with white backgrounds, and $32 \mathrm{O} 3-\mathrm{NaFe} 0.5 \mathrm{Mn} 0.5 \mathrm{O} 2$ samples are shown on gray backgrounds. Multiple cycles are shown here, obtained between 1.5 and $4.3 \mathrm{~V} v \mathrm{va} / \mathrm{Na}^{+}$at a sweep rate of $0.1 \mathrm{Vh}^{-1}$. The decrease in capacity with cycling noted in Fig. 6a of the main text is primarily due to the decrease in the peaks at high voltage (named peaks $\mathrm{c}$ and $\mathrm{d}$ in Figure S4). It is of note that two cells failed on the final cycle as clearly seen in the two plots in the bottom right here; all others continued to cycle well. 


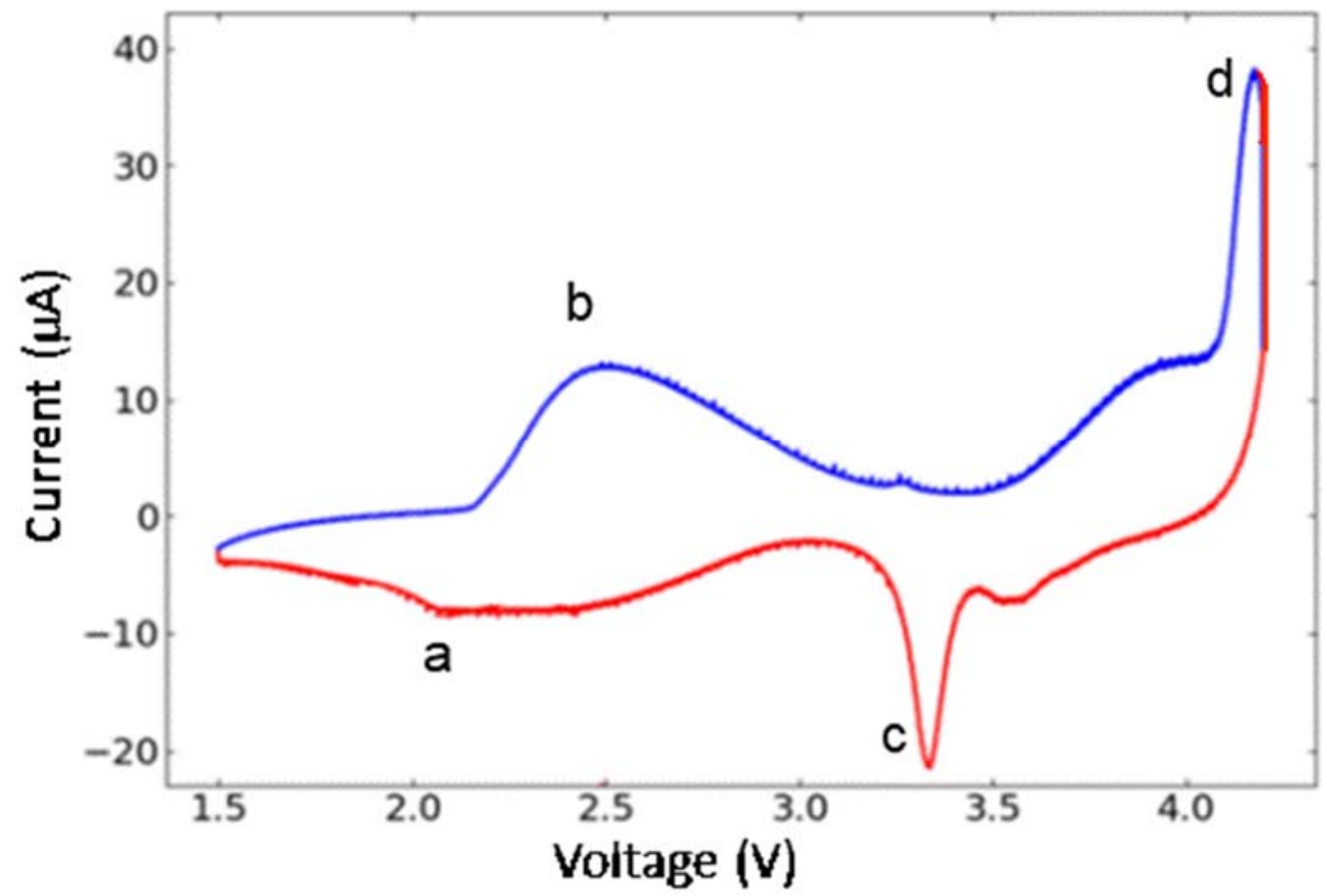

Figure S4: Cyclic voltammogram for a sample of $\mathrm{Na}_{0.66} \mathrm{Fe}_{0.5} \mathrm{Mn}_{0.5} \mathrm{O}_{2}$ with the redox peak labels used in Table 3 of the main text. 